\title{
DECAFLUOROBUTANE AS A PHASE-CHANGE CONTRAST AGENT FOR LOW-ENERGY EXTRAVASCULAR ULTRASONIC IMAGING
}

\author{
Paul S. Sheeran ${ }^{\star}$, Vincent P. Wong ${ }^{\dagger}$, Samantha Luois ${ }^{\ddagger}, \|$, Ryan J. Mcfarland", William D. \\ Ross , Steven Feingold ${ }^{\star}$, Terry O. Matsunaga ${ }^{\ddagger}, \|$, and Paul A. Dayton ${ }^{\star}$ \\ *Joint Department of Biomedical Engineering, The University of North Carolina and North \\ Carolina State University, Chapel Hill, NC, USA \\ ${ }^{\dagger}$ Biomedical Engineering Graduate Interdisciplinary Program, The University of Arizona, Tucson, \\ AZ, USA \\ FUndergraduate Biology Research Program, The University of Arizona, Tucson, AZ, USA \\ $\S$ Department of Internal Medicine, School of Medicine, The University of Arizona, Tucson, AZ, \\ USA \\ "Department of Radiology Research, The University of Arizona, Tucson, AZ, USA
}

\begin{abstract}
Currently available microbubbles used for ultrasound imaging and therapeutics are limited to intravascular space due to their size distribution in the micron range. Phase-change contrast agents (PCCAs) have been proposed as a means to overcome this limitation, since droplets formed in the hundred nanometer size range might be able to extravasate through leaky microvasculature, after which they could be activated to form larger highly echogenic microbubbles. Existing PCCAs in the sub-micron size range require substantial acoustic energy to be vaporized, increasing the likelihood of unwanted bioeffects. Thus, there exists a need for PCCAs with reduced acoustic activation energies for use in imaging studies. In this article, it is shown that decafluorobutane, which is normally a gas at room temperature, can be incorporated into metastable liquid submicron droplets with appropriate encapsulation methods. The resulting droplets are activatable with substantially less energy than other favored PCCA compounds. Decafluorobutane nanodroplets may present a new means to safely extend ultrasound imaging beyond the vascular space. (E-mail: padayton@bme.unc.edu)
\end{abstract}

\section{Keywords}

Ultrasound; Microbubble; Contrast agent; Perfluorocarbon; Acoustic droplet vaporization

(C) 2011 World Federation for Ultrasound in Medicine \& Biology.

Address correspondence to: Paul A. Dayton, Joint Department of Biomedical Engineering, The University of North Carolina and North Carolina State University, 304 Taylor Hall, CB 7575, Chapel Hill, NC 27599. padayton@ bme.unc.edu. 


\section{INTRODUCTION}

In the past two decades, gas-filled contrast agents for ultrasound (US) have been extensively explored and show promising results in applications ranging from echocardiography to molecular imaging of highly-vascularized tumors (Lindner 2009; Sboros and Tang 2010; Staub et al. 2010; Gessner and Dayton 2010; Wilson and Burns 2010). FDA-approved microbubble contrast agents (MCAs) are commonly produced with the majority of the population between 1 and $5 \mu \mathrm{m}$ in diameter to allow for safe passage through the circulatory system and provide significant contrast for imaging. Beyond imaging, microbubbles have demonstrated substantial potential for use in therapeutic applications such as drug delivery, gene delivery and thrombolysis (Ferrara et al. 2007; Hitchcock and Holland 2010; Sirsi and Borden 2009; Stride and Coussios 2010; Tinkov et al. 2009). Many tumor types exhibit characteristically permeable vasculature, with endothelial gaps typically between 200-600 $\mathrm{nm}$ and show poor lymphatic clearance, also known as the enhanced permeability and retention (EPR) effect (Hobbs et al. 1998; Campbell 2006; Torchilin 2010). A gas-filled contrast agent small enough to extravasate into tumor interstitium would ultimately be much less echogenic than commonly studied MCAs in the 1-5 $\mu \mathrm{m}$ range and would provide limited US contrast (Kaya et al. 2010). Therefore, an agent capable of clearing interendothelial gaps and subsequently being transformed into a gas-filled MCA in the 1-5 $\mu \mathrm{m}$ range would have unique possibilities. Nanoemulsions have been used in the past as drug delivery agents in conjunction with ultrasound-mediated localized delivery via radiation force/acoustic streaming (Dayton and Matsunaga 2006). Rapoport et al. (2009b) have illustrated the concept of a nanoemulsion that is small enough to accumulate at an interstitial target site and can then be converted to the gaseous state through the application of ultrasonic energy and used to aid in therapeutic dose delivery.

The application of acoustic droplet vaporization (ADV) is a potential method of designing a contrast agent that can exploit the EPR effect and provide imaging contrast in tumor extravascular space. ADV, the transition of a superheated liquid droplet into gas, was described for therapeutic and diagnostic use over a decade ago (Apfel 1998; Quay 1996). It has since been used in studies with a variety of proposed applications including aberration correction (Kripfgans et al. 2002; Haworth et al. 2008), occlusion therapy (Kripfgans et al. 2005; Zhang et al. 2010), therapeutic drug delivery (Rapoport et al. 2009b; Fabiilli et al. 2010a, 2010b), and high-intensity focused ultrasound (HIFU) and lithotripsy-based nucleation agents to enhance thermal delivery and cavitation-based bioeffects (Miller et al. 2000; Zhang and Porter 2010). While not fully understood, many of the physical mechanisms involved in ADV are in the process of being described and modeled (Ye and Bull 2004, 2006; Evans et al. 2006; Qamar et al. 2010). In brief, the vaporization of a liquid droplet depends primarily on the properties of the surrounding fluid (viscosity, ambient temperature and pressure), the droplet diameter and the energy introduced into the system (heating, mechanical energy). Often a lipid or polymer shell is used to both stabilize the droplet from coalescence and to increase the Laplace pressure exerted on it, allowing for droplets of larger size and/or lower boiling point to remain in a liquid state. Most studies involving ADV-based liposomal nano/micro-emulsions have used either stabilized or superheated liquids in the perfluorocarbon (PFC) family, as many have boiling points near 
physiologic temperatures and are similar to commonly-used MCA perfluorocarbons that have significant advantages in imaging applications with less toxicity at the small volumes used (Mattrey 1994). The most common PFCs used to date, dodecafluoropentane (DDFP) and perfluorohexane $(\mathrm{PFH})$, are liquids at room temperature. When encased in lipid or polymer shells, nano/micro-emulsions of DDFP and PFH are able to stay in solution at body temperature and can be activated by additional energy input.

Many studies have reported the variety of effects that environmental and test conditions such as ambient temperature (Fabiilli et al. 2009; Zhang and Porter 2010), fluid viscosity (Lo et al. 2006), ultrasound frequency, peak negative pressure and pulse length (Kripfgans et al. 2000; Giesecke and Hynynen 2003; Lo et al. 2007; Fabiilli et al. 2009; Schad and Hynynen 2010) can have on the vaporization threshold for a particular droplet or droplet emulsion. Other studies have shown that incorporation of nanoparticles may actually decrease the threshold, which is promising for therapeutic applications (Matsuura et al. 2009). Reports of higher interstitial pressure in the abnormal tumor microenvironment may also impact the success of phase-change contrast agents vaporizing in tumor interstitium (Ferretti et al. 2009). It has been demonstrated by these studies that raising ambient pressure increases the vaporization threshold while raising temperature decreases it. The inverse relationship between the vaporization threshold and PFC droplet diameter is also well demonstrated. Therefore, an agent with sufficient stability to extravasate into the extracellular space, yet labile enough to be vaporized at sufficiently low acoustic intensities so as to not induce unwanted bioeffects would be optimal. Most studies of phase-change contrast agents to date have shown that DDFP droplets near the desired size range vaporize with the least energy input compared with alternative compounds. The input pressure needed to vaporize them can be lowered even further by altering the duration of the excitation acoustic pulse (Lo et al. 2007). By using ultrasound frequencies above $1 \mathrm{MHz}$ and pulse-lengths in the millisecond range, micron-sized droplets can be vaporized with pressures considered safe for diagnostic procedures (Fabiilli et al. 2009). However, data suggest that the vaporization of sub-micron droplets may require substantially more energy. Thus, sub-micron ADV, which requires high mechanical indices, would enhance the possibility of bioeffects, an undesirable side effect for imaging-only applications. Choosing alternative lower boilingpoint PFCs could lower the vaporization threshold for sub-micron droplets, although they then have the potential to be relatively unstable compared with their higher boiling-point counterparts. In some applications, such as thermal ablation enhancement, droplet stability through a range of temperatures above $37^{\circ} \mathrm{C}$ may be a priority over low vaporization thresholds (Zhang and Porter 2010). Kawabata et al. (2005) have proposed that to increase stability, the lower boiling-point PFC could be used as a "volatile agent" in mixture with a "non-volatile agent" of a higher boiling point to produce agents with a lowered threshold.

In this article, it is demonstrated that decafluorobutane (DFB) may achieve the desired low vaporization threshold, even when prepared as sub-micron droplets. DFB has a boiling point of $-1.7^{\circ} \mathrm{C}$, significantly lower than other PFCs commonly used in ADV, which may allow vaporization at much lower pressures. This could, in turn, significantly decrease the chance of unwanted bioeffects due to ultrasound exposure. To date, no study of phase-change contrast agents has explored the use of DFB, which is used as a gas in several prototype US contrast agent formulations and is similar to MCA gases approved for clinical applications. 
The aim of this study is to develop a better understanding of the trade-offs inherent in choosing a lower boiling-point PFC. The results of this study show the ability to produce stable micron and sub-micron lipid-encapsulated phase-change agents that can vaporize at lower pressures than similarly-sized emulsions of higher boiling-point PFCs.

\section{MATERIALS AND METHODS}

\section{Theory}

To investigate whether DFB had potential as a phase-change contrast agent at physiologic temperatures, pilot study calculations were performed using the Antoine vapor-pressure equation, which was derived from the Clausius-Clapeyron relation by Antoine in 1888 and when re-arranged for temperature is expressed as

$$
\mathrm{T}=\frac{\mathrm{B}}{\mathrm{A}-\log _{10} \mathrm{P}}-\mathrm{C}
$$

where $\mathrm{P}$ is pressure, $\mathrm{T}$ is temperature and $\mathrm{A}, \mathrm{B}$ and $\mathrm{C}$ are gas-dependent constants observed to be valid for a particular temperature range. This equation uses experimental results to develop a basic relationship between temperature and pressure as a droplet of a particular substance vaporizes. Following reasoning outlined by Rapoport et al. (2009a), a droplet will experience an additional pressure due to interfacial surface tension effects, defined as the Laplace pressure

$$
\Delta \mathrm{P}=\mathrm{P}_{\text {inside }}-\mathrm{P}_{\text {outside }}=\frac{2 \sigma}{\mathrm{r}}
$$

where $\mathrm{r}$ is the radius of the droplet, $\sigma$ is surface tension and $\mathrm{P}_{\text {inside }}$ and $\mathrm{P}_{\text {outside }}$ represent the pressure inside the droplet core and the ambient pressure in the surrounding media, respectively. PFCs typically have fairly low surface tension values on the order of $10 \mathrm{mN} / \mathrm{m}$ at room temperature. Because the Laplace pressure is an inverse function of radius, smaller droplets will experience greater pressure. Encapsulating the droplets in a lipid or polymer shell stabilizes the droplets from coalescence and alters the interfacial surface tension. Depending on the properties of the encapsulating shell, a larger resulting surface tension may cause an increase in the pressure exerted, which essentially increases the vaporization temperature of the droplet. In designing agents for human medical imaging purposes, the ambient pressure may be defined as

$$
\mathrm{P}_{\mathrm{amb}}=\mathrm{P}_{\mathrm{atm}}+\mathrm{P}_{\text {boby }}
$$

where $\mathrm{P}_{\mathrm{atm}}=101.325 \mathrm{kPa}$ and $\mathrm{P}_{\text {body }}$ is a representative pressure inside the human body (vascular or other). Although intravascular pressure is inherently pulsatile, for the purposes of these calculations, an average value of $\mathrm{P}_{\text {body }}=12.67 \mathrm{kPa}$ was used. With a total pressure exerted on the droplet of

$$
\mathrm{P}=\mathrm{P}_{\mathrm{amb}}+\Delta \mathrm{P}=\mathrm{P}_{\mathrm{atm}}+\mathrm{P}_{\text {boby }}+\frac{2 \sigma}{\mathrm{r}}
$$

The resulting modified Antoine vapor-pressure equation is

Ultrasound Med Biol. Author manuscript; available in PMC 2015 June 01. 


$$
\mathrm{T}=\frac{\mathrm{B}}{\mathrm{A}-\log _{10}\left(\mathrm{P}_{\mathrm{atm}}+\mathrm{P}_{\text {boby }}+\frac{2 \sigma}{\mathrm{r}}\right)}-\mathrm{C}
$$

Published surface tensions often vary between $25 \mathrm{mN} / \mathrm{m}$ and $50-60 \mathrm{mN} / \mathrm{m}$, depending on surfactant properties (Alexandridis et al. 1994; Borden et al. 2004). Although the exact surface tension of lipid solutions used in this study were not known, a value near $51 \mathrm{mN} / \mathrm{m}$ was sufficient for the purposes of these initial calculations in that it provided a Laplace pressure near the upper limit of what can be expected. The constants A, B and C were gathered from the National Institute of Standards and Technology (NIST) Chemistry WebBook (Linstrom and Mallard 2010) for the nearest available temperature range. Figure 1 shows the relationship between droplet diameter and predicted vaporization temperature for octafluoropropane (OFP), decafluorobutane (DFB), dodecafluoropentane (DDFP) and perfluorohexane (PFH) (natural boiling points of $-37.6^{\circ} \mathrm{C},-1.7^{\circ} \mathrm{C}, 29^{\circ} \mathrm{C}$ and $56.6^{\circ} \mathrm{C}$, respectively). While the constants used are not expected to predict the vaporization relationship completely accurately in the desired temperature range, the calculation shows that DFB droplets appear to have the potential to remain stable in the $200-600 \mathrm{~nm}$ diameter range at temperatures just above body temperature. This suggests that they may require a small amount of additional energy (such as US) to induce vaporization compared with other PFCs, if droplets can be generated stably. Although the temperature required to induce vaporization increases substantially for droplets near 200-300 $\mathrm{nm}$ in diameter, others have shown successful vaporization of droplets through ultrasonic energy at temperatures as much as $40^{\circ} \mathrm{C}$ below their boiling point, as in the case of perfluorohexane droplets vaporizing at room and body temperature (Giesecke and Hynynen 2003; Fabiilli et al. 2010b). According to the estimations, octafluoropropane droplets have the potential to remain stable at sizes below $200 \mathrm{~nm}$, although the $-37.6^{\circ} \mathrm{C}$ boiling point presents significant production challenges. With a boiling point of $-1.7^{\circ} \mathrm{C}$, DFB droplet generation can be explored at more feasible temperatures.

Ideal gas laws (PV = nRT, where $\mathrm{n}, \mathrm{P}, \mathrm{V}$ and $\mathrm{T}$ represent the number of moles of PFC, pressure, volume and temperature, respectively) can be used to approximate the expansion factor when a liquid undergoes a phase conversion to the gaseous state. Because perfluorocarbons are immiscible in the liquid state and have low diffusivity in the gaseous state, it is assumed that the number of moles is constant from the liquid phase to the gaseous phase $\left(n_{1}=n_{g}\right)$. The moles of PFC in the spherical droplet can be computed as

$$
\mathrm{n}_{1}=\frac{4 \pi \mathrm{r}_{1}^{3} \rho_{1}}{3 \mathrm{M}}
$$

where $r_{1}$ is the radius of the liquid droplet, $\rho_{1}$ is the liquid density and $M$ is the molar mass. Substituting this into the ideal gas law and simplifying as a ratio of the gas-phase radius to liquid-phase radius gives

$$
\frac{\mathrm{r}_{\mathrm{g}}}{\mathrm{r}_{1}}=\sqrt[3]{\frac{\rho_{1} \mathrm{RT}}{\mathrm{MP}}}
$$


Expanding with eqn (4) gives

$$
\frac{\mathrm{r}_{\mathrm{g}}}{\mathrm{r}_{1}}=\sqrt[3]{\frac{\rho_{1} \mathrm{RT}}{\mathrm{M}\left(\mathrm{P}_{\text {atm }}+\mathrm{P}_{\text {boby }}+\frac{2 \sigma}{\mathrm{r}_{\mathrm{g}}}\right)}}
$$

As $r_{g}$ approaches very large values, the surface tension component becomes negligible.

Decafluorobutane has a molar mass of $\mathrm{M}=0.238 \mathrm{~kg} / \mathrm{mol}$ and at $37^{\circ} \mathrm{C}(310 \mathrm{~K}) \rho_{\mathrm{l}} \approx 1500$ $\mathrm{kg} / \mathrm{m}^{3}$. Evaluating eqn $(8)$ with in vivo $\left(\mathrm{P}_{\text {body }}=12.67 \mathrm{kPa}\right)$ and in vitro $\left(\mathrm{P}_{\text {body }}=0 \mathrm{kPa}\right)$ conditions and neglecting surface tension effects reveals that, based on the assumptions given, a droplet of DFB can be predicted to expand to an approximate upper limit of 5.2 to 5.4 times its original diameter once vaporized (neglecting any deviations from ideal gas laws). Rearranging eqn (8) such that it is solved for liquid droplet radius becomes

$$
\mathrm{r}_{1}=\sqrt[3]{\frac{\mathrm{Mr}_{\mathrm{g}}^{2}\left[\mathrm{r}_{\mathrm{g}}\left(\mathrm{P}_{\mathrm{atm}}+\mathrm{P}_{\text {boby }}\right)+2 \sigma\right]}{\rho_{1} \mathrm{RT}}}
$$

This allows one, based on ideal gas laws and surface tension effects, to estimate the size of the droplet that vaporized to become a bubble of a known size. Evans et al. (2006) show that eqn (8) can also be solved for $r_{g}$, providing a numerically equivalent, though much more complex, solution. For the purposes of this study, eqn (9) becomes a more convenient solution, as measured bubble sizes are used to estimate originating droplet sizes.

\section{Preparation of micron-sized perfluorocarbon droplets}

Lipid thin films were prepared with a lipid composition containing dipalmitoylphosphatidylcholine (DPPC), 1-palmitoyl-2-hydroxy-sn-glycero-3phosphocholine (LPC) and 1,2-dipalmitoyl-sn-glycero-3-phosphoethanolamine- $\mathrm{N}$ [methoxy(polyethylene glycol)-2000] (DPPE-PEG-2000) (Avanti Polar Lipids, Alabaster, AL, USA). Chloroform (EMD Chemicals; Gibbstown, NJ, USA) was used to dissolve the lipids, which were then dried over a stream of nitrogen gas. To remove residual solvent, the lipids were stored in vacuo overnight.

The lipid films were rehydrated with approximately $1 \mathrm{~mL}$ of $(4-(2-$ hydroxyethyl)piperazine-1-ethanesulfonic acid) (HEPES) buffer $(\mathrm{pH}=7.4)$ (Sigma-Aldrich, Co., St. Louis, MO, USA) and sonicated for $10 \mathrm{~min}$ in a water bath sonicator (Branson 1510; Branson Ultrasonic Corporation, Danbury, CT, USA) at $50-60^{\circ} \mathrm{C}$. The rehydrated films were then subjected to 10 freeze-thaw cycles. The solution was then stirred for $10 \mathrm{~min}$ at $50-60^{\circ} \mathrm{C}$. The resulting concentration of the lipid solution was approximately $20 \mathrm{mg} / \mathrm{mL}$.

Three compounds with boiling points above room temperature were selected for comparison to decafluorobutane. Perfluoro(2-methyl-3-pentanone) (PFMP), dodecafluoropentane (DDFP) and perfluorohexane (PFH) were purchased from FluoroMed (Round Rock, TX, USA). Their physical properties are listed in Table 1 (Lide 2010). Each perfluorocarbon was added to the lipid solution and multiple extrusions were performed using an Avanti mini- 
extruder (Avanti Polar Lipids, Alabaster, AL, USA) with a 19-mm 1- $\mu$ m nuclepore polycarbonate track-etch membrane filter (Whatman Ltd., Maidstone, Kent, UK) at room temperature $\left(25^{\circ} \mathrm{C}\right)$. Extrusions were completed after 20 passes through the membrane filter. Each sample was placed in a $1.5 \mathrm{~mL}$ centrifuge tube. Afterwards, the resulting emulsions underwent centrifugation using a Beckman TJ-6 centrifuge (Beckman Coulter, Inc., Brea, CA, USA) for $15 \mathrm{~min}$ at $1000 \mathrm{rpm}$. The emulsions were stored immediately in the refrigerator $\left(4^{\circ} \mathrm{C}\right)$.

\section{Preparation of micron-sized decafluorobutane droplets}

For DFB droplets (physical properties found in Table 1), the same lipid formulation was prepared. DFB (FluoroMed, Round Rock, TX, USA) gas was condensed over dry ice followed by storage into a $2 \mathrm{~mL}$ glass vial and crimped. Samples were then mixed with the corresponding lipid solution and extruded through a $13 \mathrm{~mm}$ diameter syringe holder equipped with a 1- $\mu \mathrm{m}$ Nuclepore polycarbonate track-etch membrane filters (Whatman Ltd., Maidstone, Kent, UK) in a $-20^{\circ} \mathrm{C}$ freezer to maintain the DFB in the condensed state while at the same time being careful not to freeze the solution. DFB emulsions were then sealed in a $2 \mathrm{~mL}$ vial and stored in a $4^{\circ} \mathrm{C}$ refrigerator prior to testing.

\section{Preparation of sub-micron-sized decafluorobutane droplets}

Sub-micron droplets were prepared using a newly developed condensation method whereby microbubbles of desired size were prepared followed by pressurization and condensation to generate the DFB-condensed droplets (patent pending). The volumetric change produced for each condensed bubble resulted in a sample of liquid DFB droplets with a majority in the sub-micron range.

\section{Sizing droplets}

Perfluorocarbon emulsions were prepared for sizing on a Malvern Nano ZetaSizer (Malvern Instruments Ltd., Malvern, Worcestershire, UK). The ZetaSizer was set to automatically detect up to three local distribution peaks (multi-modal). Briefly, a $150 \mu \mathrm{L}$ sample was introduced into a $12 \mathrm{~mm}$ disposable square polystyrene cuvette and $1 \mathrm{~mL}$ of HEPES buffer was added. The associated software was utilized to help identify the average sizes of the droplets along with the dispersity and size distributions.

\section{Experimental apparatus}

A water bath constructed of acrylic was mounted on top of an inverted microscope (Olympus IX71) and interfaced with a high-speed camera (FastCam SA1.1, Photron USA, Inc., San Diego, CA, USA) to capture monochrome videos and still images of particles and microbubbles (Fig. 2). A $\times 100$ water immersion objective with a working distance of 1.5 $\mathrm{mm}$ was used to provide image magnification. The optical resolution of the system was measured to be approximately $0.5 \mu \mathrm{m}$, as determined by a polystyrene latex sphere resolution test (Ted Pella, Inc., Redding, CA, USA). Baseline water oxygen saturation was measured to be 5 parts per million (PPM) at $37^{\circ} \mathrm{C}$, as measured by a chemical test kit (Oxygen CHEMets, CHEMetrics, Inc., Calverton, VA, USA). In the case of degassed experiments, an in-line degasser was allowed to operate until the water oxygenation in the 
water tank measured less than or equal to 1.5 PPM. The water bath was passively heated to a consistent $37^{\circ} \mathrm{C}$ by heating water in an auxiliary tank and continuously pumping it through copper coils lining the main tank such that vibration in the water bath was minimized. The temperature of the auxiliary tank was adjusted until the desired temperature of the water in the experiment region of the main tank along with any additional light-heating was reached. The dropletsolution was pumped through a nearly optically and acoustically transparent cellulose tube with a $200 \mu \mathrm{m}$ inner diameter (Spectrum Labs, Inc., Greensboro, NC, USA) using a custom-built manual injector allowing for precise administration of the droplets into the field of view. A 3-axis micropositioner (MMO-203; Narishige Group, East Meadow, NY, USA) was utilized to manipulate the sample holder and, therefore, the droplets/bubbles in the field of view. By this means we were able to locate and manipulate droplets to stay on-screen throughout the test and track the resulting bubbles.

\section{Acoustics}

A spherically focused $5 \mathrm{MHz}$ transducer with a focal length of $3.8 \mathrm{~cm}$ (IL0506HP; Valpey Fisher Corp., Hopkinton, MA, USA) was used to insonify droplet samples. The transducer had $-6 \mathrm{~dB}$ beam widths of $0.7 \mathrm{~mm}$ laterally and $13.2 \mathrm{~mm}$ axially for peak positive pressure, while widths were $1.3 \mathrm{~mm}$ laterally and $22.8 \mathrm{~mm}$ axially for peak negative pressure. Waveforms were constructed using an arbitrary waveform generator (AWG 2021; Tektronix, Inc., Beaverton, OR, USA), which allowed for adjustment of the transmission waveform pulse length and amplitude. A manually-triggered signal of adjustable amplitude was used for these experiments consisting of a 10-cycle sinusoid at $5 \mathrm{MHz}$ resulting in a total insonification time of $2 \mu \mathrm{s}$. A synchronization pulse from the waveform generator was relayed to the high speed camera to trigger a marker with the acoustic pulse on the digital video. The waveform from the function generator was amplified approximately $60 \mathrm{~dB}$ using an RF amplifier (A500; ENI, Rochester, NY, USA) to excite the transducer. For opticalacoustic alignment, the transducer focus was matched with the optical focus by positioning the tip of a needle hydrophone (HNA-0400; Onda Corp., Sunnyvale, CA, USA) in center of the microscope field of view. The transducer was then calibrated at focus over the range of amplitudes used so that the pressure exerted on the droplets in the field of view was known.

\section{Analysis of images}

Still images and videos were captured and stored on a computer using proprietary camera software (PFV; Photron USA, Inc., San Diego, CA, USA). The software was set to start recording just before the manually-triggered ultrasound signal so that the transition from droplet to bubble could be observed continuously. Image analysis was performed on the recordings (ImageJ; NIH, Bethesda, MD, USA) to calculate the diameter of the droplets and resulting bubbles.

\section{Vaporization threshold of individual PFC droplets and subsequent diameter}

The vaporization threshold of individual PFC droplets was performed by first venting the undiluted samples with a 20-gauge needle and then diluting in phosphate-buffered saline (PBS) until only one to two droplets were visible on screen at any particular time after injection into the cellulose tube. This typically ranged from $1-20 \mu \mathrm{L} / \mathrm{mL}$ PBS and depended 
on the concentration of larger droplets present in the original sample. In the degassed experiments, the PBS, which normally measured approximately 6 PPM oxygen, was placed under vacuum prior to dilution until the oxygenation measured less than or equal to 3 PPM so that both the water tank and diluent were degassed. As larger PFC droplets tended to flow near the bottom of the cellulose tube due to weight and because the largest droplet on screen vaporizes with the least amount of energy input, there was little chance of out-of-focus droplets, which tended to be very small and toward the top of the tube, interfering with vaporization threshold determination. The droplets were held on screen with the position manipulator and ultrasound pressure in the form of a $2 \mu$ s pulse at $5 \mathrm{MHz}$ was increased in incremental steps of approximately $0.115 \mathrm{MPa}$ with $1-2 \mathrm{~s}$ of rest time between each trigger. The earliest pressure that induced observed vaporization was recorded to correlate to droplet diameter and the tube was shifted by micro-manipulator so that the focus was fully on the resulting bubble diameter. This diameter of the bubble was observed and measured over several seconds to capture any phenomena. For analysis, the pressure that induced vaporization was converted to mechanical index (MI), defined as:

$$
\frac{\text { Peak Negative Pressure }(\mathrm{MPa})}{\sqrt{\text { US Frequency }(\mathrm{MPz})}}
$$

When switching between samples, the cellulose tube was either re-made with new tubing or flushed with a sequence of: (1) $1 \mathrm{~mL} 95 \%$ ethanol, (2) $3 \mathrm{~mL}$ of air and (3) $1 \mathrm{~mL}$ de-ionized water and for tests involving larger droplets inspected optically to ensure no droplets were present in the remaining fluid.

\section{Sub-micron droplet vaporization threshold and estimation of vaporized droplet size}

Due to the fact that droplets smaller than $1 \mu \mathrm{m}$ challenged the resolution capabilities of the experimental setup, the approach to sub-micron droplet vaporization differed from the individual PFC droplet approach. Samples generated by the microbubble condensation method were diluted to approximately $300 \mu \mathrm{L} / \mathrm{mL}$ PBS to increase the number of viable droplets in the field of view. Sample sizing was performed by dynamic light scattering to ensure they consisted of sub-micron sized droplets only. Other studies have shown that large outliers, which would likely vaporize first, could impact the vaporization threshold of remaining droplets (Lo et al. 2007). After optical verification that no micron-sized droplets were present in the sample, the top of the cellulose tube was brought into focus to verify that no bubbles were present prior to the US energy. Samples were insonified using a $5 \mathrm{MHz}$ sinusoid with a pulse length of $2 \mathrm{~ms}$ and the pressure increased until a significant number of bubbles of sizes less than $5 \mu \mathrm{m}$ were consistently produced. The pressures used by this method, therefore, are not direct vaporization thresholds, but are rather "activation" values that are seen to vaporize the majority of the content in the bulk sample so that its contents can be measured. By the ideal gas law estimations delineated above, bubbles with diameters of $5 \mu \mathrm{m}$ or less should result from droplets originally sized less than $1 \mu \mathrm{m}$. The resulting bubbles floated to the top of the tube after the acoustic pressure was applied and were "scrolled" through using the volume position manipulator. Bubbles were counted, measured and correlated to sizing results as indirect evidence of sub-micron droplet vaporization. 


\section{RESULTS}

Several hundred droplets of DFB, DDFP, PFMP and PFH were insonified with varying ultrasound pressure at $5 \mathrm{MHz}$. A total of 153 successfully vaporized droplets across all PFCs investigated were evaluated for the relationship between initial diameter and pressure required for vaporization, as well as resulting bubble characteristics.

\section{Droplet sizing and optical verification}

DFB, DDFP, PFMP and PFH extrusion through membrane filters resulted in sub-micron and micron-sized droplets. As the upper measurement limit of the Malvern ZetaSizer was $6 \mu \mathrm{m}$ in diameter, the range of droplets larger than those measured was not captured, but the largest DFB droplet observed optically after being heated to $37^{\circ} \mathrm{C}$ over all tests performed was measured to be approximately $13 \mu \mathrm{m}$ in diameter. DFB droplet generation by the microbubble condensation method resulted in primarily sub-micron droplet distributions with diameter peaks near $300 \mathrm{~nm}$ and a range typically from 200-600 nm (Fig. 3).

Information about initial droplet concentration was not obtained through the sizing techniques used, but did not affect the results, as each sample was diluted to an optimal concentration for each test.

\section{Vaporization threshold for individual perfluorocarbon droplets}

Through high-dilution, individual PFC droplets were exposed to ultrasound peak negative pressures ranging from 1.43 MPa to $4.97 \mathrm{MPa}$ during the course of the $2 \mu$ s signal, or a mechanical index between 0.64 and 2.22. Vaporization of DFB, DDFP and PFMP droplets in the 1-30 $\mu$ m diameter range was recorded optically and the vaporization threshold plotted as a function of initial droplet diameter (Fig. 4). PFH droplets, the largest of which measured approximately $9 \mu \mathrm{m}$, were unable to be vaporized at the pressures used for this study and are not represented in the figure. Studies by others have shown that PFH can be vaporized in other test conditions and size ranges. A minimum of 15 droplets of each PFC were used to curve-fit threshold values across the size range. The average diameter of both DFB and DDFP droplets vaporized in this set of experiments was $5 \pm 3 \mu \mathrm{m}$ while PFMP droplets measured an average of $14 \pm 6 \mu \mathrm{m}$. As demonstrated by many studies, the vaporization threshold appeared to increase as the droplet diameter decreased. Curves that produced the best fits for the vaporized droplets were logarithmic, resulting in $\mathrm{R}^{2}$ values of $0.84,0.84$ and 0.74 for DFB, DDFP and PFMP, respectively. For the smaller droplet sizes observed, the pressure required to vaporize DDFP and PFMP was approximately 50\% and 75\% more than that required for DFB, respectively. As droplet size increased, the difference in activation pressure compared with DFB decreased, reducing to only $30 \%$ and $60 \%$ more pressure for DDFP and PFMP, respectively, for droplets of approximately $10 \mu \mathrm{m}$.

All micron-sized droplets of DFB were seen to vaporize at a MI lower than 1.5, while comparable pressures were only able to vaporize droplets greater than $10 \mu \mathrm{m}$ in size for both comparison PFCs. The relatively short $2 \mu$ s was sufficient to induce vaporization for all PFCs other than PFH. Additionally, bubbles created by vaporization of DFB droplets were subjected to secondary pulses administered several seconds after formation, during which no instances of bubble destruction were observed. 


\section{Observation of resulting bubble diameter in gassed and de-gassed experiments}

The experimental set-up allowed for verification of specific droplet vaporization, so resulting bubbles could be correlated directly to the initial droplet diameter. This continuous observation allowed for noting of any effects that occurred subsequently to vaporization. Ideal gas laws at these initial sizes predict that the phase-change should result in a gas bubble approximately 5.2-5.4 times larger than the original droplet diameter. During the course of the vaporization thresholds in the un-degassed experimental setup, it was noticed that the resulting bubbles tended to be much larger than the predicted size. Because the bubbles were continually observed in an extremely dilute state, it could be confirmed that this did not occur due to bubble coalescence after droplet vaporization. The experiment was repeated in a degassed experimental set-up for both DFB and DDFP and the resulting diameter plotted as a function of initial diameter (Fig. 5). The results in the un-degassed experiment follow an approximately linear fit $\left(R^{2}=0.84\right)$, while the degassed results show a strongly linear fit $\left(\mathrm{R}^{2}=0.98\right)$. The average un-degassed expansion over 46 observed droplets was $10 \pm 2$ times the original diameter, while the degassed experiment resulted in an average expansion over 37 droplets of $6 \pm 1$ times the original diameter. In both cases the increase in expansion beyond the predicted values did not appear correlated to initial droplet diameter. Two videos of individual bubbles observed over a longer time period were analyzed for both degassed and un-degassed setups. Figure 6 shows examples of the observed phenomenon in both scenarios. The bubbles in the un-degassed experiments grew an average of $22 \%$ of their original observed diameter over the experiment duration, while those in the degassed experiments only grew an average of $4 \%$ over the same time period.

\section{Vaporization of sub-micron decafluorobutane droplets}

For vaporized droplets produced by microbubble condensation, an average MI of 1.71 (a peak negative pressure of $3.82 \mathrm{MPa}$ ) consistently produced microbubbles with sizes $5 \mu \mathrm{m}$ or smaller. Immediately prior to vaporization, no droplets or bubbles were present in the frame. Once ultrasound pressure was applied, droplets were immediately present (Fig. 7). In many instances, bubbles larger than $5 \mu \mathrm{m}$ were observed that did not correlate well to the sizing results. Observing the resulting bubbles over several seconds in multiple tests showed that bubbles resulting from this droplet generation technique were much more prone to coalescence than for droplets made by extrusion, potentially due to the difference in lipid concentration between the two methods, which could account for the presence of larger bubbles. The resulting measured bubble diameters within optical resolution produced over several tests with the same conditions (outliers greater than $5 \mu$ m excluded), had a mean of 2 $\pm 1 \mu \mathrm{m}(\mathrm{N}=148)$.

\section{DISCUSSION}

In this study, the vaporization threshold for micron and sub-micron sized decafluorobutane droplets was examined in contrast to other commonly studied perfluorocarbons to determine efficacy as a candidate phase-change contrast agent in applications such as intra-tumoral deposition and imaging. The results show that lipid-encapsulated DFB droplets can be successfully manufactured in the micron and sub-micron range by membrane extrusion. The additional pressure exerted by the lipid membrane on the liquid droplet was proven 
sufficient to keep small-sized droplets in solution at physiologically relevant temperatures prior to vaporization by additional energy input, in this case by ultrasound at clinically relevant frequencies and pressures.

These results serve as an early indicator of the high potential of DFB as a future phasechange contrast agent, especially for extravascular applications. The curve fit to the thresholds of individual droplets predicts an increasing gap in the energy difference needed to vaporize DFB when compared with its higher-boiling-point counterparts as the droplet diameter decreases. For example, a $300 \mathrm{~nm}$ droplet of DDFP with the same short waveform and frequency used in these tests is predicted by the curve fits to require approximately a MI of 2.69 to vaporize, while a DFB droplet is only predicted to require a MI of 1.78, below the current clinical limit of 1.9 for diagnostic imaging. The demonstrated threshold values for DDFP seem to be consistent within the range reported by others in similar experiments, although longer pulse lengths were used in most other studies. Lo et al. (2007) as well as others, demonstrated that the vaporization threshold for perfluorocarbon droplets could be lowered by increasing signal pulse length and by increasing US frequency used. It is possible that the same techniques could be applied to further lower the vaporization threshold for DFB to values below the currently presented ones.

The pulse lengths used in this study were relatively short, so that the temperature increase induced by the acoustic signal can be assumed to be negligible. This implies that the thresholds observed by this study were probably due mostly to mechanical effects such as those outlined by Kripfgans et al. (2004). Whether or not the curves fit to vaporization thresholds accurately predict the pressure required for submicron-sized droplets of both DDFP and DFB necessitates further studies. It can be reasonably argued that as the diameter of the droplet is reduced into the nanometer range, the observed effects at the micrometer scale will not predict those at the nanometer scale.

The observation that bubbles tended to be larger than anticipated in a gas-saturated environment matches that of Kripfgans et al. (2000). Their study posits that the resulting bubbles may expand due to absorption of dissolved gases present in the host fluid, which is in line with our observation of gradual bubble growth over a several-second time period. We were able to optically observe the transition of individual droplets into the resulting bubbles and confirm that almost immediately after vaporization was induced, the resulting bubble was larger than that predicted by ideal gas laws. The optical set-up also allowed for confirmation that bubbles were not the result of the effects of coalescence. In the case of undegassed fluid, the resulting bubble averaged an expansion factor of 10 over initial droplet size, while in the degassed set-up the expansion factor was 6 . We hypothesize that the expansion factor observed with the degassed set-up, which was higher than ideal gas predictions, was likely due to the diffusion of dissolved gas still present (oxygenation measured at 1.5 PPM). In both cases, the measurements were made within seconds after vaporization and even after this measurement the bubbles appeared to still be growing in diameter gradually. We estimated that the growth rate was four to five times as quick in the case of un-degassed fluid, which explains the higher variation in the measured expansion factor (some may have had more time to expand than others prior to measurement). A recent experimental study by Wong et al. (2011) used ultra-high speed imaging to show that bubble 
evolution on a very short timescale appears to occur in several stages immediately after vaporization and plateaus at an expansion factor close to the theoretical value within approximately $150 \mu$ s independent of droplet size. The presence of a lipid shell could serve to damp the intake of dissolved gases and result in gradual growth over a much longer period after vaporization, although determining whether bubbles approach a maximal or steady-state size will require future studies. The initial results suggest that ADVagents may experience a similar effect post-vaporization with regard to gas-saturation levels as Kwan and Borden (2010) recently modeled for gas-filled MCAs. In applications where an upper limit on bubble size is essential, thorough studies of the effect of local gas-saturation will be needed to ensure that the bubble does not expand to beyond the required size and cause unwanted effects. Although some tumors are known to be hypoxic, they cannot be assumed to be gas-free and, therefore, an expansion beyond that predicted by ideal gas laws may be observed in practice.

The results produced using the higher-concentration sub-micron droplet solutions provide promising evidence that vaporization of sub-micron sized DFB droplets is, in fact, feasible at relevant pressures for diagnostic imaging. Bubbles that most likely resulted from submicron droplets of DFB were produced using a mechanical index of 1.71 and a single pulse of only $2 \mu$ s, which would also avoid heating-based bioeffects. With such short pulse lengths, it is unlikely that these bubbles resulted from fractioning of larger bubbles or any similar effects.

As a second step of indirect proof for sub-micron droplet vaporization, the bubble measurements obtained from this set of experiments were used to estimate the size of the originating droplets for comparison with the initial particle sizing. The experimentally observed expansion factor of 6 for droplets in the micrometer range was not used for this estimation due to the assumption that surface-tension effects will become much more dominant for droplets in the nanometer range. It also cannot be assumed that the observed expansion due to ambient dissolved gas will affect the expansion of nanometer-sized droplets as it does micron-sized droplets due to the significantly increased internal pressure of the droplet. Therefore, ideal gas law estimations are preferable in this size range. Equation (9) was evaluated for 148 measured bubbles with the parameters $\mathrm{P}_{\mathrm{amb}}=101.325$ $\mathrm{kPa}$ and a surface tension of $\sigma=30 \mathrm{mN} / \mathrm{m}$, which is suitable for the lipid solution used for these droplets. A histogram of the estimated droplet sizes that produced the measured bubbles (Fig. 8) shows that the peak estimated droplet sizes occurred in the 300-350 nm bin, which matches extremely well with the original sizing results produced by dynamic light scattering (Fig. 3). The histogram appears to be skewed to the right of the central peak, which may be anticipated due to the stochastic nature of droplet vaporization, even at sufficient pressures to vaporize droplets smaller than $350 \mathrm{~nm}$, droplets larger than $350 \mathrm{~nm}$ will vaporize with greater efficiency. The curve fits for DFB in the micron-sized droplet experiments predict a MI of 1.78 for vaporization of $300 \mathrm{~nm}$ droplets, which is in good agreement with the observed MI of 1.71 necessary to vaporize content near this size. The lipid formulations varied significantly between the two generation methods and so vaporization thresholds may be lower for these nanometer-scale droplets than the curve-fits 
predict. These observations taken together provide strong evidence that vaporization of submicron DFB droplets can be achieved with feasible diagnostic imaging pressures.

Evaluating eqn (9) for differing parameter values reveals the effect of scaling on the interplay of ambient pressure and Laplace pressure (Fig. 9). For droplets in the nanometer size range, surface tension effects become dominant and the largest expansion is predicted by the lowest surface tension. A transition occurs at the low micrometer range, resulting in ambient pressure becoming the dominant effect on expansion for larger droplets. The largest expansion in this region can be predicted by the lowest ambient pressure. Additionally, a sharp decline in the expansion factor is observed as droplet sizes approach the lower nanometer range. This can have fundamental implications in design of phase-change contrast agents for purposes of extravasation. To take advantage of the EPR effect, droplets of 100-200 nm in size would be ideal, resulting in enhanced intratumoral diffusion.

However, once these droplets are vaporized, they may only increase by a factor of 2.5-3.5 times the original diameter, resulting in bubbles on the order of $250-700 \mathrm{~nm}$. While bubbles of this size may still be useful for cavitation-based effects and enhancing thermal therapy or drug delivery, they are much smaller than preferable for diagnostic imaging, where bubbles are ideally on the order of 1-5 $\mu \mathrm{m}$. Through post-extravasation droplet/bubble coalescence, these may still provide increased echogenicity, although no studies have characterized to what degree this type of coalescence may actually occur in vivo. Therefore, there exists a design trade-off in echogenicity and droplet diffusivity. Droplets near $250-350 \mathrm{~nm}$ in size will likely still diffuse into interstitial space due the EPR effect and will produce bubbles on the order of $1 \mu \mathrm{m}$ or greater, providing ideal image enhancement for applications such as early tumor detection and real-time confirmation of targeted therapeutic delivery.

In all of the tests on DFB droplets, short pulse lengths appeared to be adequate to activate both micron and sub-micron sized droplets at clinically relevant pressures. In practice, it may be possible to further reduce the likelihood of unwanted bioeffects by creating a custom activation/imaging pulse. A brief "activation" pulse could be delivered at the front-end of each frame acquisition followed by gathering of image lines at a much lower MI, rather than imaging at the "activation" MI for the entirety of the imaging session. This is similar to commonly-employed functional diagnostic imaging schemes centered on contrast agent perfusion imaging in kidney and tumor vasculature, where a high-MI pulse is used to destroy contrast agents and lower-MI pulses are used to image the subsequent vascular reperfusion.

\section{CONCLUSION}

It has been shown that decafluorobutane can be successfully generated as lipid-encapsulated micron and sub-micron sized droplets that remain stable at physiologic temperatures. Most studies of phase-change contrast agents to date have chosen PFCs that are stable at room temperature, presumably due to simplicity of droplet generation. This study is the first, to the knowledge of the authors, which has explored the use of lower boiling-point PFCs by using shell encapsulation to produce stable liquid droplets from PFCs that are normally gas at room and body temperature. Further investigations are needed to characterize the stability of DFB droplets in vitro and in vivo as well as potential bio-effects in vivo. DFB-based 
phase-change contrast agents show significant potential for applications such as intratumoral deposition of chemotherapeutics and the imaging of interstitial space.

\section{Acknowledgments}

The authors appreciate the assistance of Drs. Russell Mumper and Michael Jay in the UNC Eshelman School of Pharmacy for assistance with sub-micron particle sizing and the assistance of Roshni Kothadia and Suraj Patel in image analysis. This project was supported by the National Institutes of Health through grant EB011704. Paul Sheeran has been partially supported by a graduate fellowship from the National Science Foundation.

\section{References}

Alexandridis P, Athanassiou V, Fukuda S, Hatton TA. Surface activity of poly(ethylene oxide)-blockpoly(propylene oxide)-block-poly(ethylene oxide) copolymers. Langmuir. 1994; 10:2604-2612.

Apfel R. Activatable infusable dispersions containing drops of a superheated liquid for methods of therapy and diagnosis. US Patent No. Nov 24.1998 5(840): 276.

Borden MA, Pu G, Runner GJ, Longo ML. Surface phase behavior and microstructure of lipid/PEGemulsifier monolayer-coated micro-bubbles. Colloids Surf B Biointerfaces. 2004; 35:209-223. [PubMed: 15261034]

Campbell RB. Tumor physiology and delivery of nanopharmaceuticals. Anticancer Agents Med Chem. 2006; 6:503-512. [PubMed: 17100555]

Dayton PA, Matsunaga TO. Ultrasound-mediated therapies using oil and perfluorocarbon-filled nanodroplets. Drug Dev Res. 2006; 67:42-46.

Evans DR, Parsons DF, Craig VS. Physical properties of phase-change emulsions. Langmuir. 2006; 22:9538-9545. [PubMed: 17073477]

Fabiilli ML, Haworth KJ, Fakhri NH, Kripfgans OD, Carson PL, Fowlkes JB. The role of inertial cavitation in acoustic droplet vaporization. IEEE Trans Ultrason Ferroelectr Freq Control. 2009; 56:1006-1017. [PubMed: 19473917]

Fabiilli ML, Haworth KJ, Sebastian IE, Kripfgans OD, Carson PL, Fowlkes JB. Delivery of chlorambucil using an acoustically-triggered perfluoropentane emulsion. Ultrasound Med Biol. 2010a; 36:1364-1375. [PubMed: 20691925]

Fabiilli ML, Lee JA, Kripfgans OD, Carson PL, Fowlkes JB. Delivery of water-soluble drugs using acoustically triggered perfluorocarbon double emulsions. Pharm Res. 2010b; 27:2753-2765. [PubMed: 20872050]

Ferrara K, Pollard R, Borden M. Ultrasound microbubble contrast agents: Fundamentals and application to gene and drug delivery. Annu Rev Biomed Eng. 2007; 9:415-447. [PubMed: 17651012]

Ferretti S, Allegrini PR, Becquet MM, McSheehy PM. Tumor interstitial fluid pressure as an earlyresponse marker for anticancer therapeutics. Neoplasia. 2009; 11:874-881. [PubMed: 19724681]

Gessner R, Dayton PA. Advances in molecular imaging with ultrasound. Mol Imaging. 2010; 9:117127. [PubMed: 20487678]

Giesecke T, Hynynen K. Ultrasound-mediated cavitation thresholds of liquid perfluorocarbon droplets in vitro. Ultrasound Med Biol. 2003; 29:1359-1365. [PubMed: 14553814]

Haworth KJ, Fowlkes JB, Carson PL, Kripfgans OD. Towards aberration correction of transcranial ultrasound using acoustic droplet vaporization. Ultrasound Med Biol. 2008; 34:435-445. [PubMed: 17935872]

Hitchcock KE, Holland CK. Ultrasound-assisted thrombolysis for stroke therapy: Better thrombus break-up with bubbles. Stroke. 2010; 41:S50-S53. [PubMed: 20876505]

Hobbs SK, Monsky WL, Yuan F, Roberts WG, Griffith L, Torchilin VP, Jain RK. Regulation of transport pathways in tumor vessels: Role of tumor type and microenvironment. Proc Natl Acad Sci USA. 1998; 95:4607-4612. [PubMed: 9539785]

Kawabata K, Sugita N, Yoshikawa H, Azuma T, Umemura S. Nanoparticles with multiple perfluorocarbons for controllable ultrasonically induced phase shifting. Jpn J Appl Phys (Part 1). $2005 ; 44: 4548-4552$. 
Kaya M, Feingold S, Hettiarachchi K, Lee AP, Dayton PA. Acoustic responses of monodisperse lipid encapsulated microbubble contrast agents produced by flow focusing. Bubble Sci Eng Technol. 2010; 2:33-40. [PubMed: 21475641]

Kripfgans OD, Fabiilli ML, Carson PL, Fowlkes JB. On the acoustic vaporization of micrometer-sized droplets. J Acoust Soc Am. 2004; 116:272-281. [PubMed: 15295987]

Kripfgans OD, Fowlkes JB, Miller DL, Eldevik OP, Carson PL. Acoustic droplet vaporization for therapeutic and diagnostic applications. Ultrasound Med Biol. 2000; 26:1177-1189. [PubMed: 11053753]

Kripfgans OD, Fowlkes JB, Woydt M, Eldevik OP, Carson PL. In vivo droplet vaporization for occlusion therapy and phase aberration correction. IEEE Trans Ultrason Ferroelectr Freq Control. 2002; 49:726-738. [PubMed: 12075966]

Kripfgans OD, Orifici CM, Carson PL, Ives KA, Eldevik OP, Fowlkes JB. Acoustic droplet vaporization for temporal and spatial control of tissue occlusion: A kidney study. IEEE Trans Ultrason Ferroelectr Freq Control. 2005; 52:1101-1110. [PubMed: 16212249]

Kwan JJ, Borden MA. Microbubble dissolution in a multigas environment. Langmuir. 2010; 26:65426548. [PubMed: 20067292]

Lide, DR. Handbook of chemistry and physics. 90. Boca Raton, FL: CRC Press/Taylor and Francis; 2010. Internet Version 2010

Lindner JR. Contrast ultrasound molecular imaging of inflammation in cardiovascular disease. Cardiovasc Res. 2009; 84:182-189. [PubMed: 19783842]

Linstrom, PJ.; Mallard, WG. NIST Chemistry WebBook, NIST Standard Reference Database Number 69. Gaithersburg, MD 20899: National Institute of Standards and Technology; 2010.

Lo AH, Kripfgans OD, Carson PL, Fowlkes JB. Spatial control of gas bubbles and their effects on acoustic fields. Ultrasound Med Biol. 2006; 32:95-106. [PubMed: 16364801]

Lo AH, Kripfgans OD, Carson PL, Rothman ED, Fowlkes JB. Acoustic droplet vaporization threshold: Effects of pulse duration and contrast agent. IEEE Trans Ultrason Ferroelectr Freq Control. 2007; 54:933-946. [PubMed: 17523558]

Matsuura N, Williams R, Gorelikov I, Chaudhuri J, Rowlands J, Hynynen K, Foster S, Burns P, Resnik N. Nanoparticle-loaded perfluorocarbon droplets for imaging and therapy. 2009 IEEE Int Ultrason Symp (IUS). 2009:5-8.

Mattrey RF. The potential role of perfluorochemicals (PFCS) in diagnostic-imaging. Artif Cells Blood Substitutes Immobilization Biotechnol. 1994; 22:295-313.

Miller DL, Kripfgans OD, Fowlkes JB, Carson PL. Cavitation nucleation agents for nonthermal ultrasound therapy. J Acoust Soc Am. 2000; 107:3480-3486. [PubMed: 10875392]

Qamar A, Wong ZZ, Fowlkes JB, Bull JL. Dynamics of acoustic droplet vaporization in gas embolotherapy. Appl Phys Lett. 2010; 96:143702. [PubMed: 20448802]

Quay SC. Phase Shift Colloids as Ultrasound Contrast Agents. US Patent. Sep 24.1996 558(5):853.

Rapoport NY, Efros AL, Christensen DA, Kennedy AM, Nam KH. Microbubble generation in phaseshift nanoemulsions used as anticancer drug carriers. Bubble Sci Eng Technol. 2009a; 1:31-39. [PubMed: 20046899]

Rapoport NY, Kennedy AM, Shea JE, Scaife CL, Nam KH. Controlled and targeted tumor chemotherapy by ultrasound-activated nanoemulsions/microbubbles. J Control Release. 2009b; 138:268-276. [PubMed: 19477208]

Sboros V, Tang MX. The assessment of microvascular flow and tissue perfusion using ultrasound imaging. Proc Inst Mech Eng H. 2010; 224:273-290. [PubMed: 20349819]

Schad KC, Hynynen K. In vitro characterization of perfluorocarbon droplets for focused ultrasound therapy. Phys Med Biol. 2010; 55:4933-4947. [PubMed: 20693614]

Sirsi S, Borden M. Microbubble compositions, properties and biomedical applications. Bubble Sci Eng Technol. 2009; 1:3-17. [PubMed: 20574549]

Staub D, Schinkel AF, Coll B, Coli S, van der Steen AF, Reed JD, Krueger C, Thomenius KE, Adam D, Sijbrands EJ, ten Cate FJ, Feinstein SB. Contrast-enhanced ultrasound imaging of the vasa vasorum: From early atherosclerosis to the identification of unstable plaques. JACC Cardiovasc Imaging. 2010; 3:761-771. [PubMed: 20633855] 
Stride EP, Coussios CC. Cavitation and contrast: The use of bubbles in ultrasound imaging and therapy. Proc Inst Mech Eng H. 2010; 224:171-191. [PubMed: 20349814]

Tinkov S, Bekeredjian R, Winter G, Coester C. Microbubbles as ultrasound triggered drug carriers. J Pharm Sci. 2009; 98:1935-1961. [PubMed: 18979536]

Torchilin VP. Passive and active drug targeting: Drug delivery to tumors as an example. Handb Exp Pharmacol. 2010; 197:3-53. [PubMed: 20217525]

Wilson SR, Burns PN. Microbubble-enhanced US in body imaging: What role? Radiology. 2010; 257:24-39. [PubMed: 20851938]

Wong ZZ, Kripfgans OD, Qamar A, Fowlkes JB, Bull JL. Bubble evolution in acoustic droplet vaporization at physiological temperature via ultra-high speed imaging. Soft Matter. 2011; 7:4009-4016.

Ye T, Bull JL. Direct numerical simulations of micro-bubble expansion in gas embolotherapy. J Biomech Eng. 2004; 126:745-759. [PubMed: 15796333]

Ye T, Bull JL. Microbubble expansion in a flexible tube. J Biomech Eng. 2006; 128:554-563. [PubMed: 16813446]

Zhang M, Fabiilli ML, Haworth KJ, Fowlkes JB, Kripfgans OD, Roberts WW, Ives KA, Carson PL. Initial investigation of acoustic droplet vaporization for occlusion in canine kidney. Ultrasound Med Biol. 2010; 36:1691-1703. [PubMed: 20800939]

Zhang P, Porter T. An in vitro study of a phase-shift nanoemulsion: A potential nucleation agent for bubble-enhanced HIFU tumor ablation. Ultrasound Med Biol. 2010; 36:1856-1866. [PubMed: 20888685] 


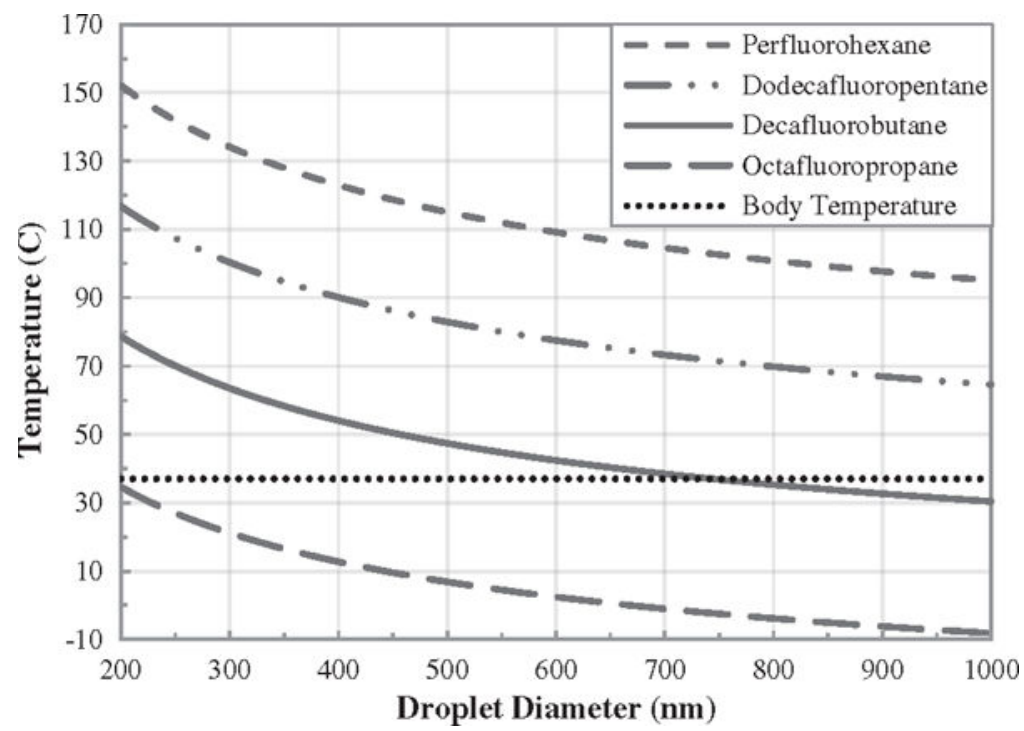

Fig. 1.

Predicted vaporization temperature of lipid-encapsulated perfluorocarbons based on Antoine vapor pressure equation. As droplet diameter decreases, the temperature required to vaporize increases exponentially. 


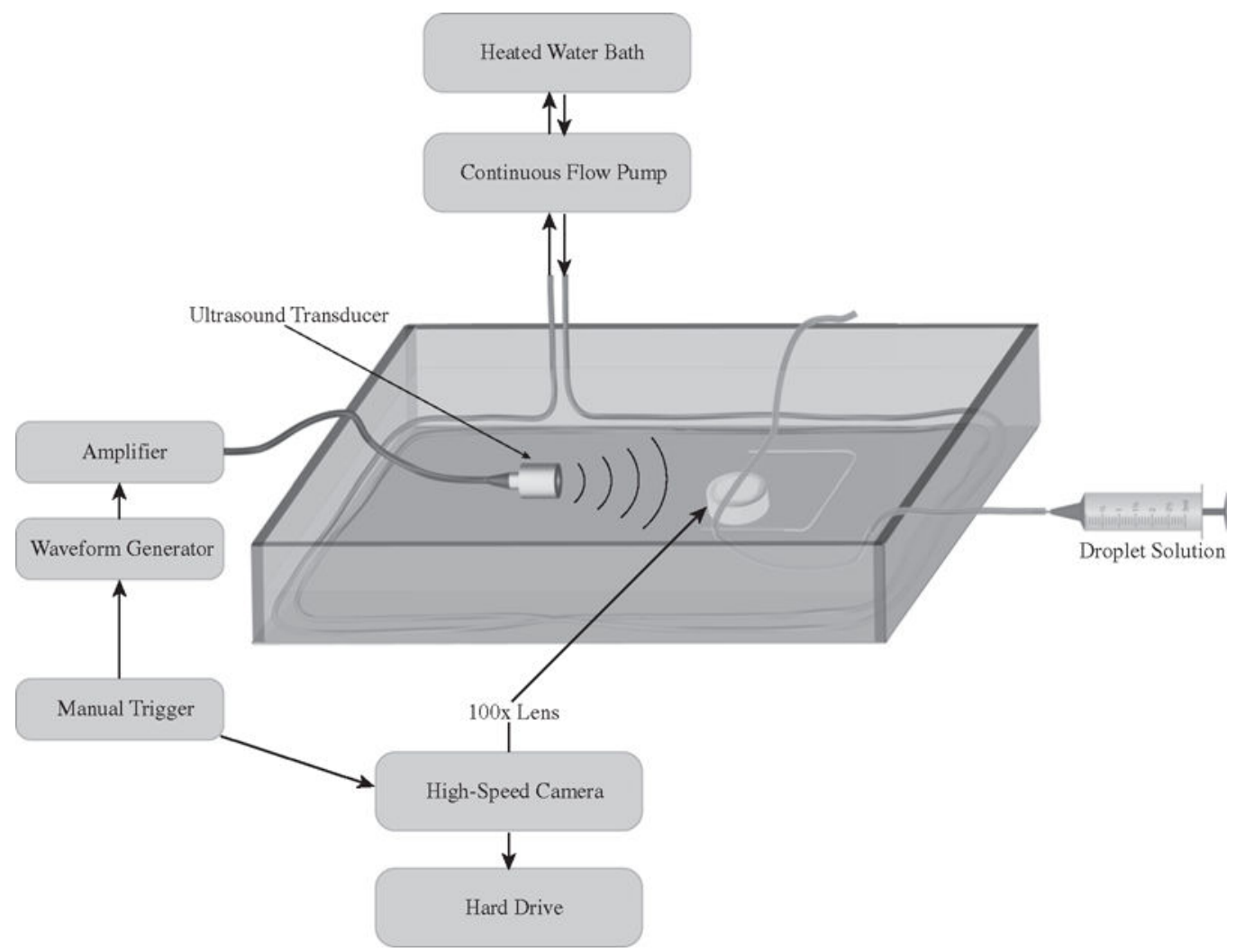

Fig. 2.

Experimental set-up for vaporization of perfluorocarbon (PFC) droplets. 


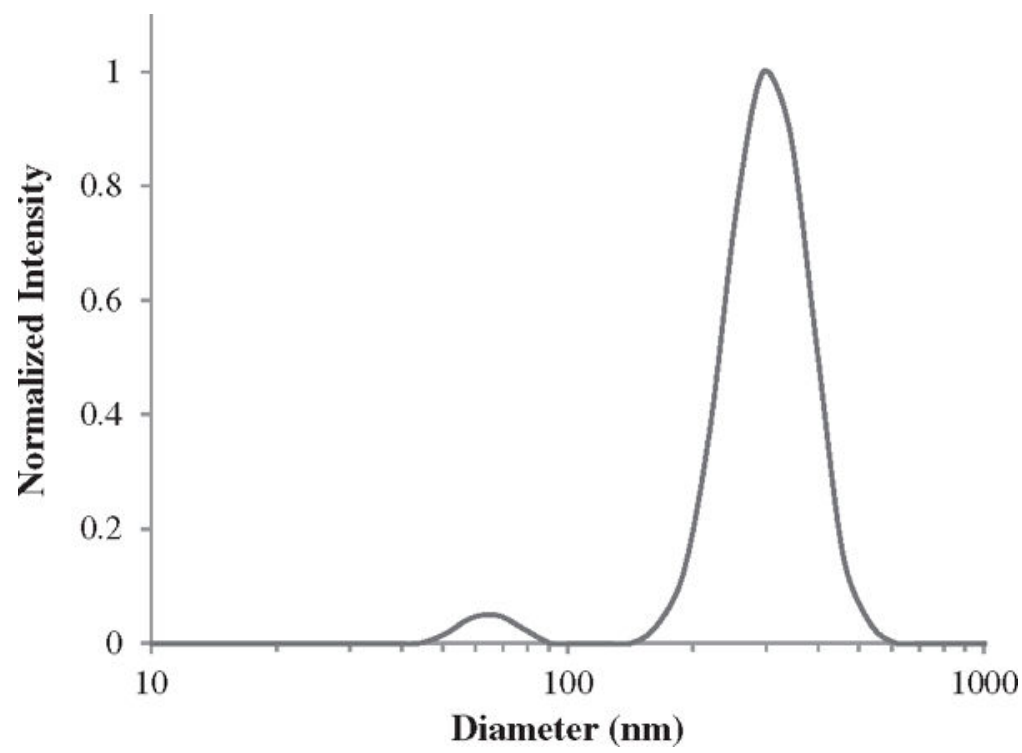

Fig. 3.

Dynamic light scattering sizing results for a decafluorobutane (DFB) droplet sample produced by microbubble condensation. 


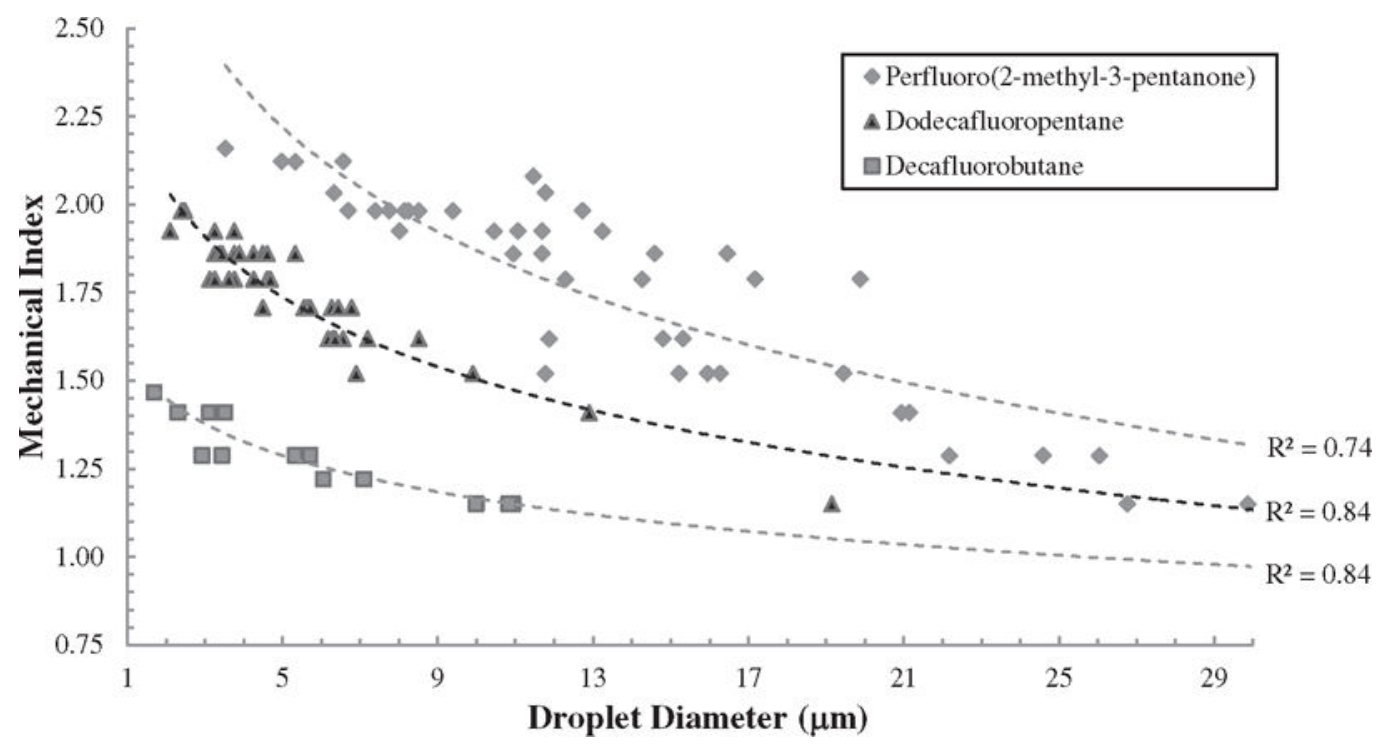

Fig. 4.

Vaporization threshold of individual droplets as a function of initial droplet diameter for decafluorobutane (DFB), dodecafluoropentane (DDFP) and perfluoro(2-methyl-3pentanone) (PFMP) droplets sonicated at $5 \mathrm{MHz}$ with a $2 \mu$ s pulse. The curves fit to the measurement points are $\mathrm{MI}_{\mathrm{DFB}}=-0.18 \ln (\mathrm{d})+1.57, \mathrm{MI}_{\mathrm{DDFP}}=-0.34 \ln (\mathrm{d})+2.28$ and $\mathrm{MI}_{\mathrm{PFMP}}=-0.50 \ln (\mathrm{d})+3.03$, where $\mathrm{d}$ is the droplet diameter in $\mu \mathrm{m}$. 


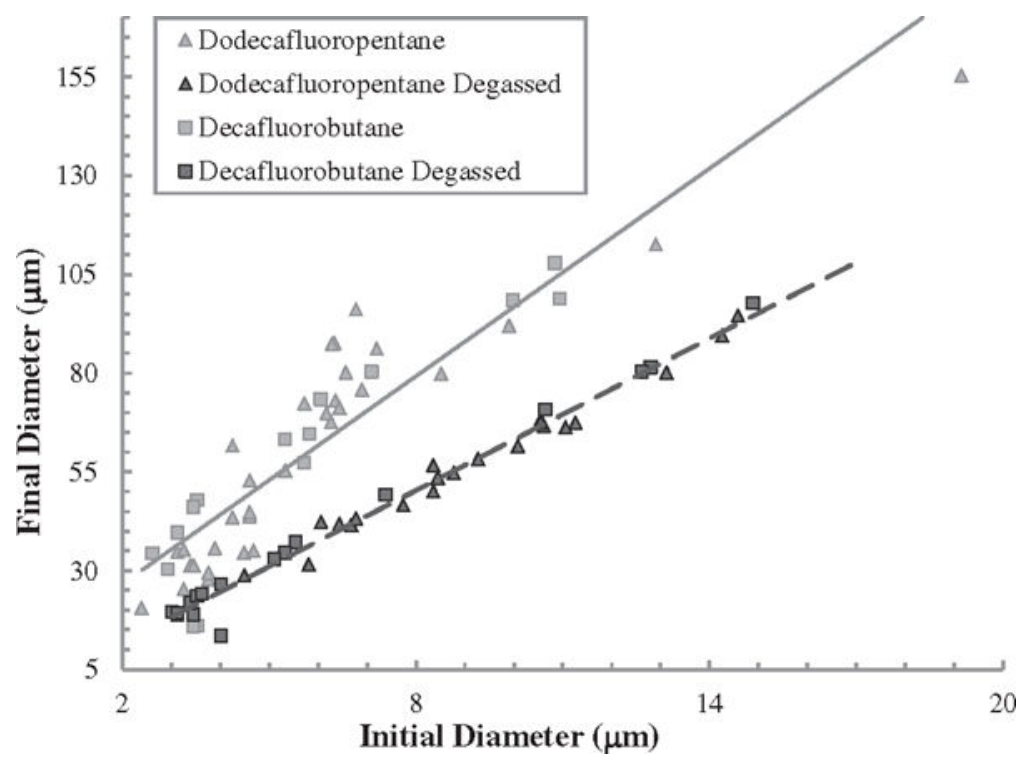

Fig. 5.

Bubble size post-vaporization for both dodecafluoropentane (DDFP) and decafluorobutane (DFB) shows a dependence on the dissolved gas level of the local fluids. Bubbles in a degassed environment showed resulting sizes nearer to those predicted by ideal gas laws, while normal tests resulted in bubbles significantly larger than the predicted size. 


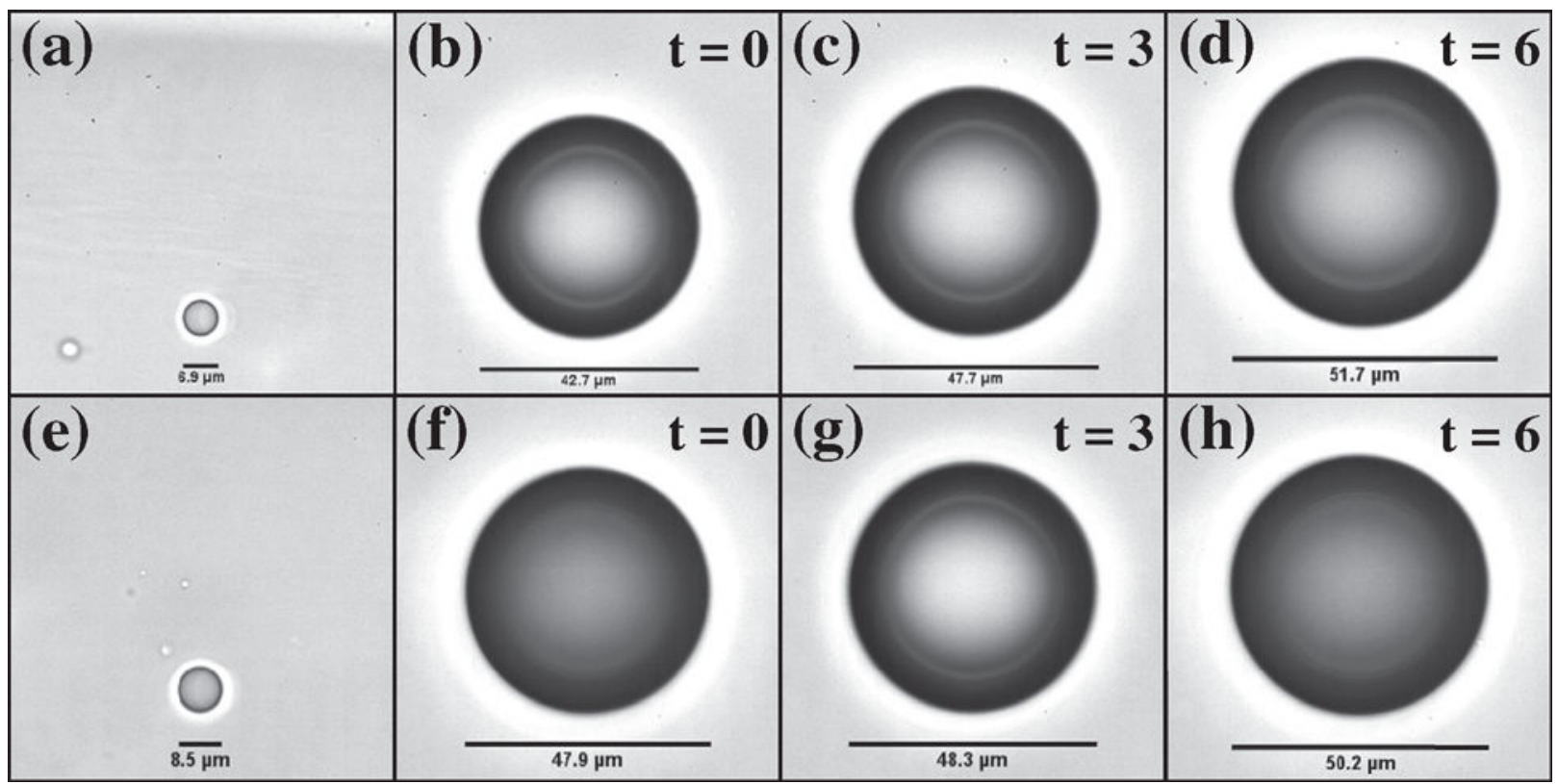

Fig. 6.

Bubble growth from individual droplets observed over several seconds. (a) through (d) show an $\sim 7 \mu \mathrm{m}$ droplet in a normal test environment growing to a bubble near $52 \mu \mathrm{m}$ after $6 \mathrm{~s}$ of observation. In a test using degassed fluids, (e) through (h) show an $\sim 8.5 \mu \mathrm{m}$ droplet growing to approximately $50 \mu \mathrm{m}$ after the same time period. Note: in (a) and (e), other spherically shaped particles are out-of-focus debris on the cellulose tube, not viable perfluorocarbon (PFC) droplets. 


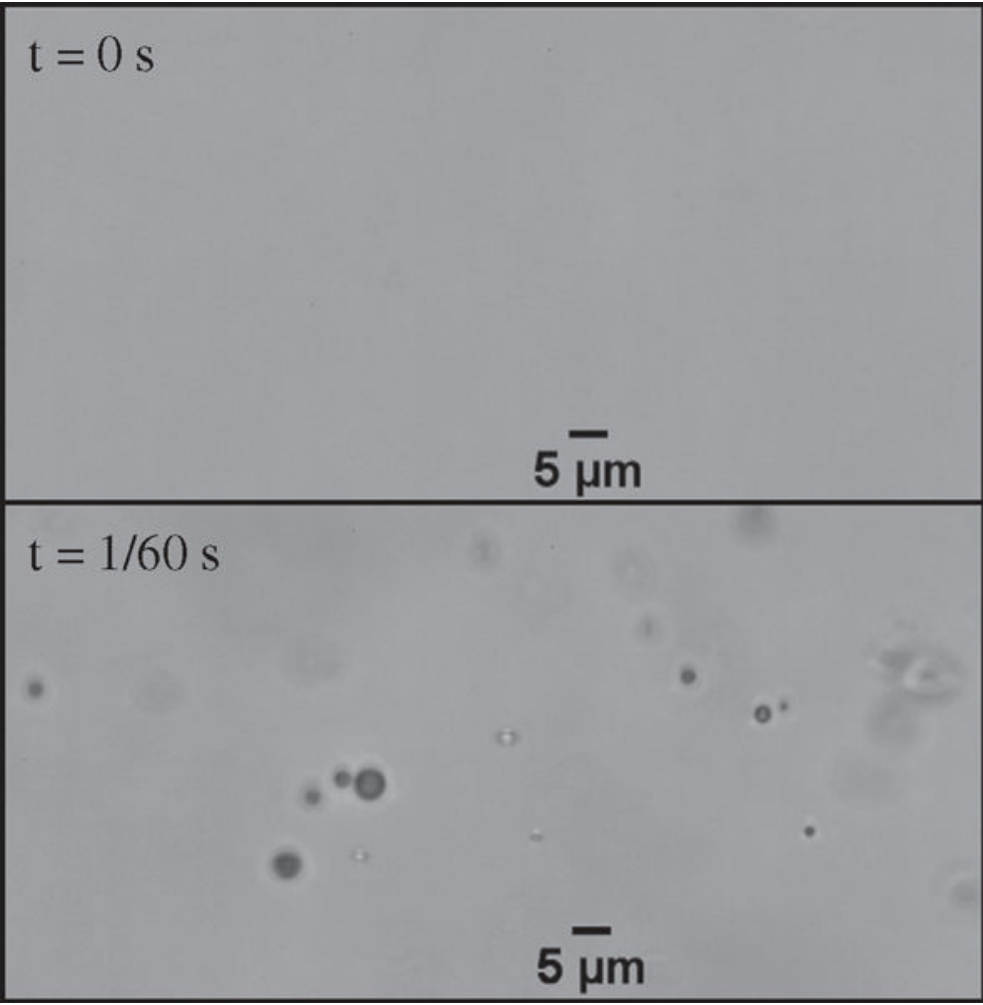

Fig. 7.

Still-frame images before and immediately after submicron decafluorobutane (DFB) sample was subject to an ultrasound pulse at a mechanical index (MI) of 1.71 . 


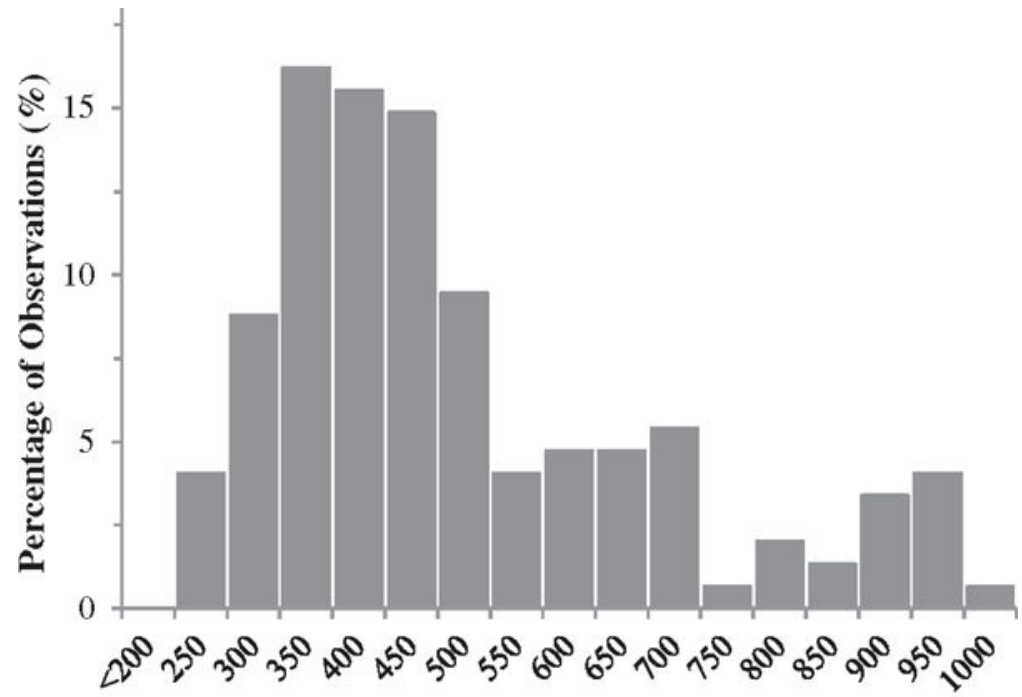

Diameter (nm)

Fig. 8.

Histogram of estimated size of droplets resulting from observed bubbles $5 \mu \mathrm{m}$ or smaller (N $=148)$. 


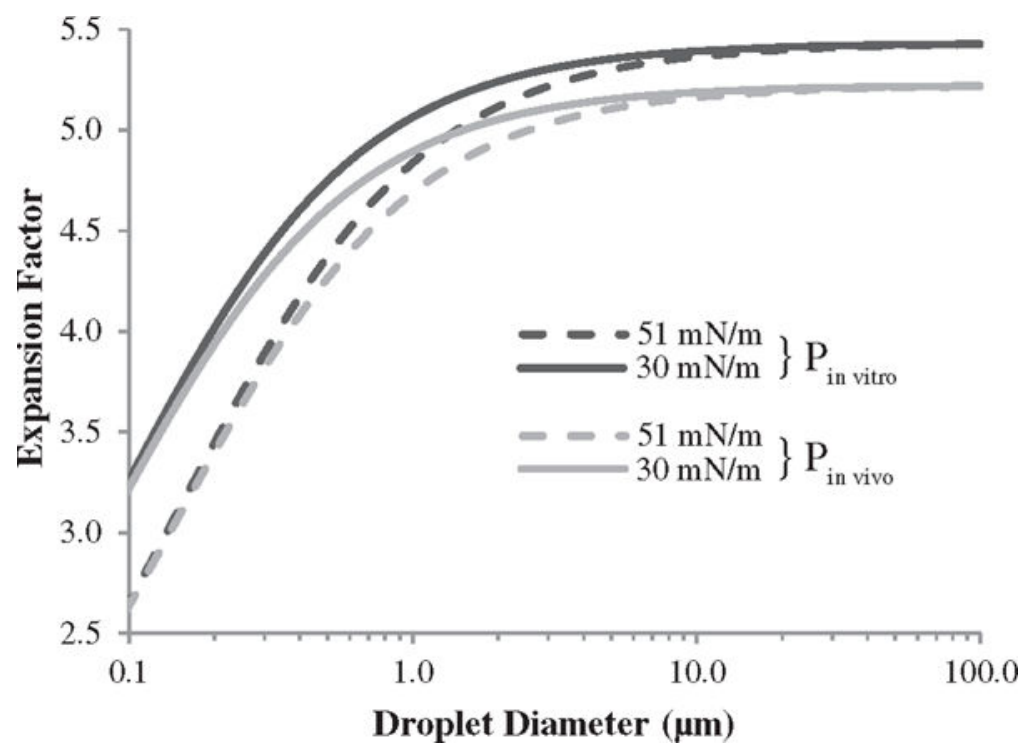

Fig. 9.

Effect of droplet size on expansion factor according to ideal gas laws with Laplace pressure included. Calculations are presented for two variations of both ambient pressure $\left(\mathrm{P}_{\text {in vitro }}=\right.$ $\left.\mathrm{P}_{\mathrm{atm}} ; \mathrm{P}_{\text {in vivo }}=\mathrm{P}_{\mathrm{atm}}+\mathrm{P}_{\text {body }}\right)$ and surface tension $\left(\sigma_{1}=30 \mathrm{mN} / \mathrm{m} ; \sigma_{2}=51 \mathrm{mN} / \mathrm{m}\right)$. Droplets on the order of $10 \mathrm{~mm}$ can be expected to expand less in vivo than in vitro regardless of surface tension, while droplets $500 \mathrm{~nm}$ or less will expand less at higher surface tension values. 

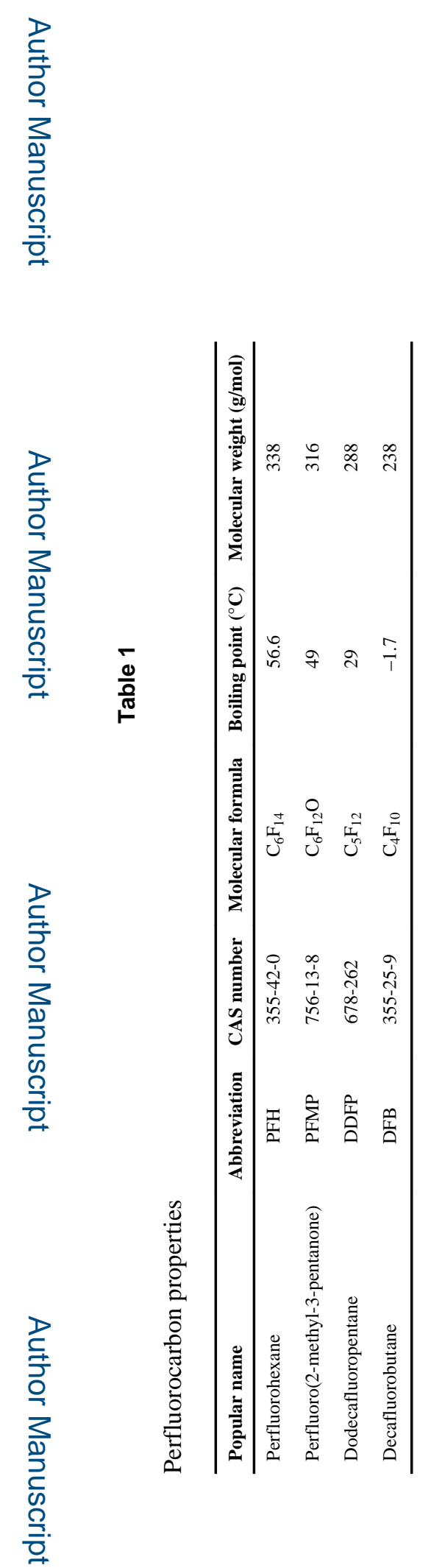

Ultrasound Med Biol. Author manuscript; available in PMC 2015 June 01. 